\title{
Developing and Implementing a Web-Based Platform for Skills and Knowledge Exchange
}

Amani Al-Ghamdi, Dalal Al Harbi, Naseebah Alarfaj, AlBandari Al Hajri, Ibrahim Almarashdeh, Mutasem k. Alsmadi, Muneerah Alshabanah, Daniah Alrajhi

Department of Management Information Systems, College of Applied Studies and Community Service, Imam Abdurrahman Bin Faisal University, Al-Dammam, Saudi Arabia

\section{ABSTRACT}

The emergence of computer networking, e-mail and computer conferencing for exchange of scientific information encouraged the adoption of a collaborative learning approach to meet the needs of both learners. The platform aims to improve community culture and knowledge by allowing the exchange of skills within the community through a free electronic platform. It aims to shorten the distance between individuals and enrich the content of the platform with new courses including computer science, engineering, programming, artificial intelligence and space sciences. The platform aims to establish partnerships and cooperation agreements with regional and international leading institutions to exchange and develop skills and expertise. Also to improve and facilitate the process of communication between the parties to the maximum extent which ensures the success of the exchange process. The proposed system was developed using the Unified Modeling Language (UML) and Microsoft Visual Studio2010 programming language.

Keywords : Skill Provider, Skill Recipient, Exchange Platform, Skills Exchange, Analysis, Design, Skills.

\section{INTRODUCTION}

Many individuals who desire to learn have difficulties to acquire skills from the competent authorities because skills are provided to groups more than individuals, in addition to the lack of financial resources for all individuals that enable them to acquire the skill, especially that most of the providers of skills provide it in exchange for money and also it is difficult for some individuals to go to distant areas to gain that skill [1]. Therefore, this project is a free Arab platform that acts as a collaborative medium between individuals, through which the exchange of skills between two parties in an interactive manner.

"Hello Pal" It is a useful application for those who wish to learn foreign languages. Through which people can talk to native speakers and improve personal skills through the direct communication when you sign in to the app, you can then select the language of the speaker and determine the language you want to learn, with country, gender, and other specifications. As a result, you can get a list of people who are willing to communicate with them [2]. Figure 1 shows the main interface for Hello Pal platform. Hello Pal has the following advantages:

- It displays examples of the most common conversation starters.

- Add text chat and share photos with others.

- Send voice messages to correct pronunciation and improve a person's skills.

- This program supports different languages such as Arabic, English, French, Italian, Hindi and other languages. 


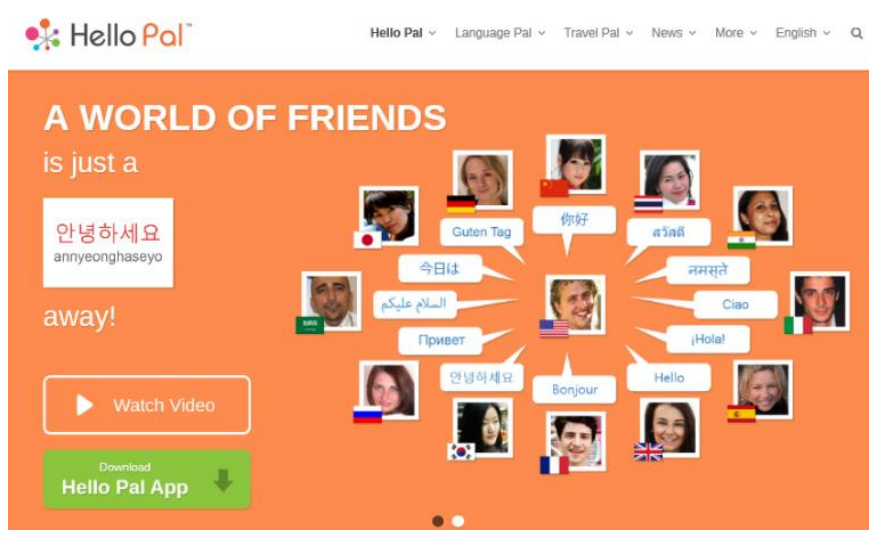

Figure 1: Hello Pal interface [2].

"Edraak" makes quality education in Arabic accessible to all internet users and promotes lifelong learning, whether for higher education or professional development. Edraak provides a platform for a diverse range of free online courses, offered by top universities and entities [3]. They do this by harnessing regional and global Arab talent to leverage technology developed by the Harvard-MIT consortium, edX. The Edraak platform also serves the important purpose of presenting Arab youth with new regional role models, the disadvantage for this platform that it relies entirely on learning from educational professionals only. Education through a learning platform that relies entirely on learning from educational professionals only. Figure 2 shows the main interface for Edraak platform.

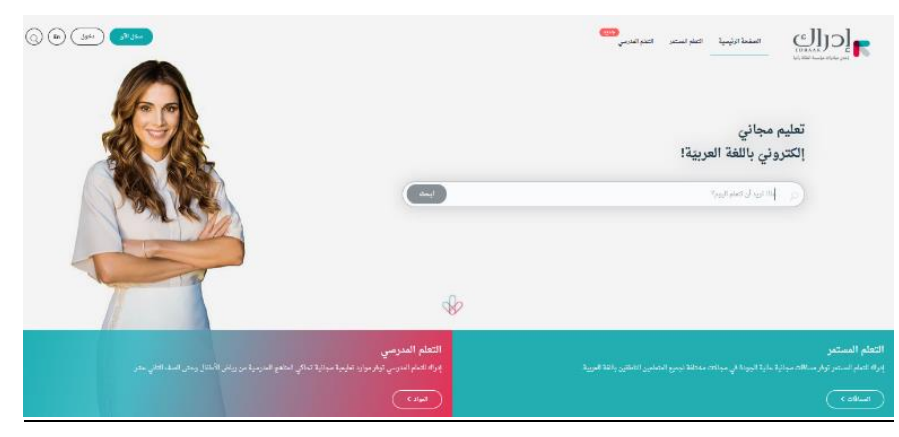

Figure 2: Edraak interface [3].

"Rwaq" is An electronic learning platform that offers free academic subjects in Arabic in all fields and disciplines, offered by distinguished academics from around the Arab world. They are keen to expand the circle of users from their specialized scientific and knowledge stock. They seek to communicate it to those outside the university walls [4]. Figure 3 shows the main interface for Rwaq platform.

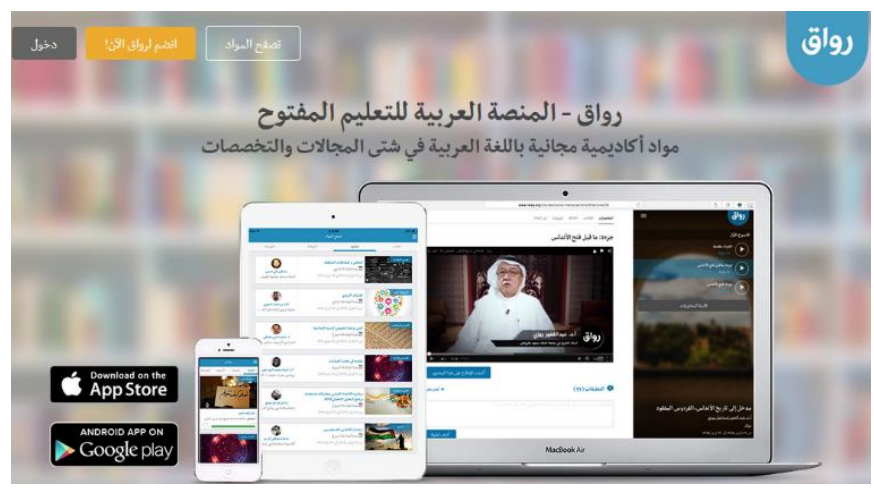

Figure 3: Rwaq interface [4].

The technological revolution influenced everything [5-25], even the methods that aim to improve the community culture and knowledge by allowing the exchange of skills within the community through a free electronic platform. Today, the use of Artificial Intelligence (AI) algorithms is expansive, particularly in providing solutions to challenging problems including patterns recognition and retrieval of information [20, 26-42], image segmentation [5, 6, 16, 43-48], analysis of medical images [49-53], Learning Management System [54-79], nurse rostering problem [80], Healthcare Monitoring system [19, 81], as well as prediction of river flow [82-84]. Accordingly, many researchers have used the Artificial Intelligence as an effective tool for skills and knowledge exchange [85-87].

\section{Methodology}

The process of system analysis aims to study an existing system to entirely design a new system. System analysis is performed to achieve mainly two aims namely: 
- To understand the process or the system clearly. This will assist in the new system design.

- System analysis will help to identify the problems in the existing system; therefore this will help to know the inefficiency reasons.

The Unified Modeling Language (UML) is visualization for the system design, it represents graphical notations which help to describe and design software systems, principally software systems constructed utilizing the object-oriented style [88-92]. The UML was utilized mainly to design the proposed system. The Use-case diagram and the Context diagram are addressed below.

\section{Use Case Diagram}

The Use-Case Model depicts system requirements. Use-case captures the communication between system, users and other stakeholders in order to achieve the intended goal of the system. It shows the interaction between the system and external entities [76, 91, 93-95]. The Actors are external entities who represent roles. They could be external hardware, human users or other systems. In this case the actors are the System Administrator, User (Skill Receiver and Skill Provider). Figure 4 shows the use case diagram for the proposed system.

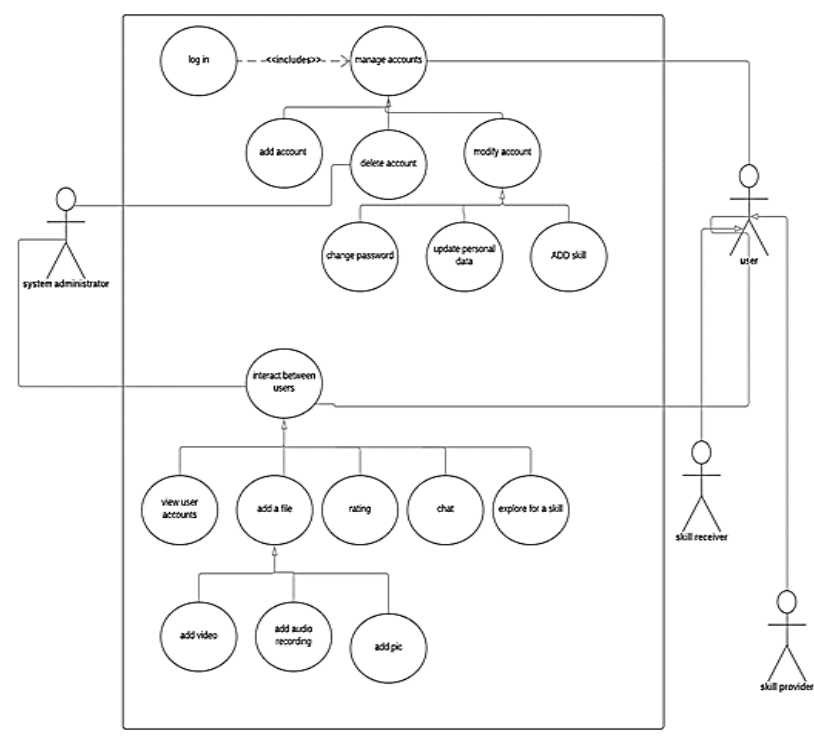

Figure 4: Use case diagram for the proposed system.

\section{Context Diagram}

The Context Diagram (CD) is used to establish the boundaries and context of the system to be modeled; where things outside and inside of the system are being modelled, and the relationship of these external entities with the system is also demonstrated [96]. CD sometimes is called a level 0 data-flow diagram, it is drawn in order to clarify and define the boundaries of the software system. It identifies the information flow between the external entities and system [96]. Figure 5 shows the Context Diagram for the proposed system.

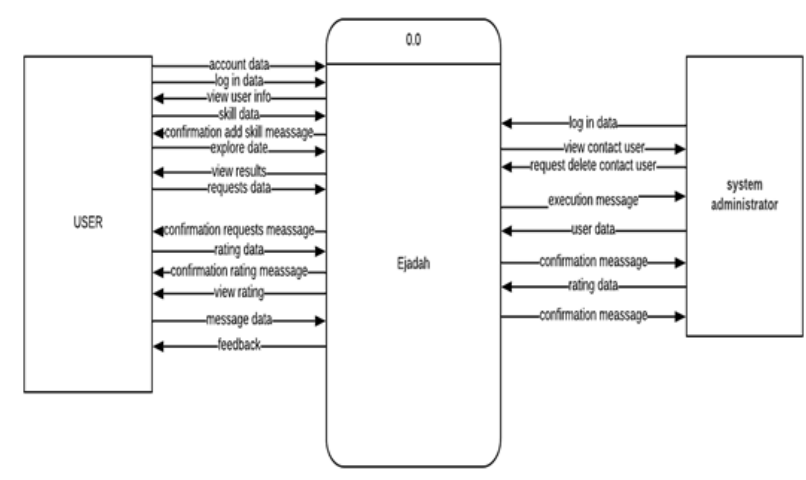

Figure 5: The Context Diagram for the proposed system.

\section{Entity Relationship (ER) Diagram}

The ER Diagram, a kind of flowchart demonstrates the way that entities such as concepts, objects, or people are related within a system to each other. ER Diagrams are commonly utilized to debug or design relational databases in the education and research, business information systems and software engineering [97 18, 17, 14]. ER diagrams are associated to Data Structure Diagrams (DSDs), which concentrates on the elements relationships within entities rather than the relationships between entities themselves. In addition, ER diagrams are commonly employed along with data flow diagrams (DFDs), which delineate the information flow for systems or 
processes. Figure 6 shows the ER diagram for the proposed system.

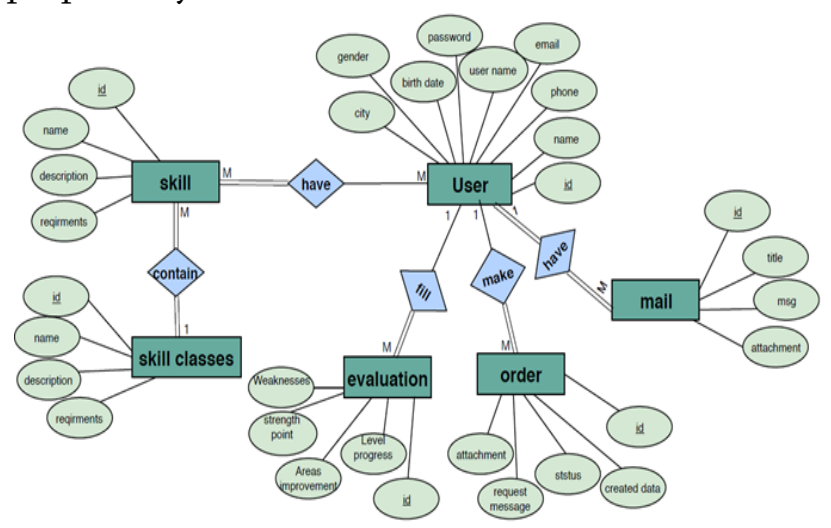

Figure 6: ER diagram for the proposed system

\section{Interface Design}

The programming language utilized in this work was Microsoft Visual Studio 2010 programming languages. The programming languages are chosen relying on the languages features which make them more suitable for this work. In the proposed system, the user starts with the registration in the system; after that the system offers the user a form for login and the user has to enter the information required. If the information is found correct by the system search in the database, it displays to the user the system homepage and allows the user to make use of the proposed system. However, if it's not valid, the user will be redirected to the login page. The figures below are examples of the designed and implemented interfaces.

\section{الرئيسية I نحن ا المهارات | اتصل بنا}

تسجيل
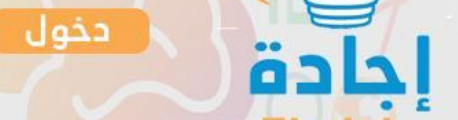

Ejadah

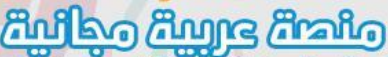

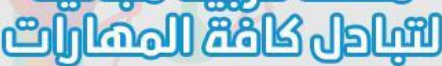

Figure 7: Main interface.

\section{الرئيسية ا نحن I اتصل بنا}

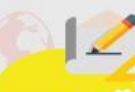

mionat

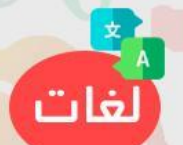

נח
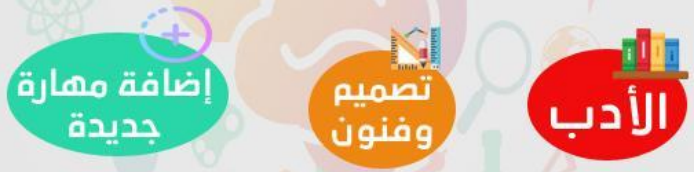

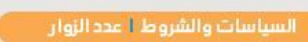

Figure 8: Skills provider interface 


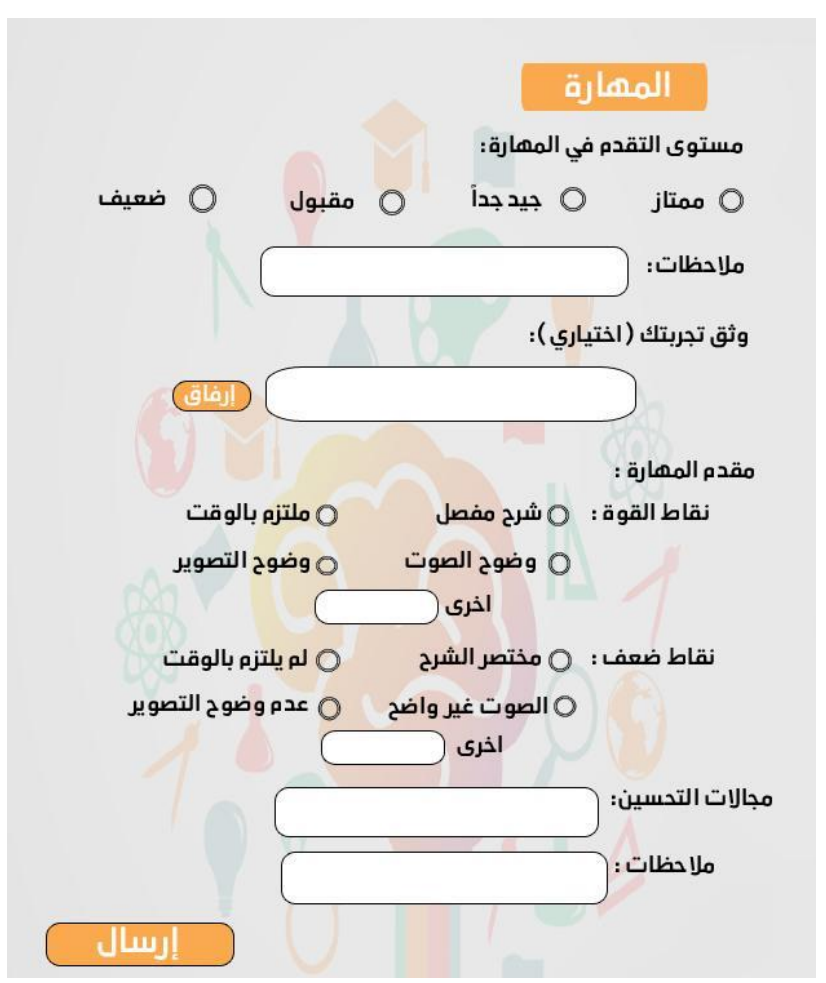

Figure 9: Review the skills provider interface.

\section{IV.Discussion}

This stage highlights the usability of the proposed system. During this stage, the system is evaluated while user satisfaction is ensured. Test was executed on the proposed system by running it on Mozilla Firefox and Internet Explorer using the local host server. For evaluation purpose, 20 students from College of Applied Studies and Community Service at Imam Abdurrahman Bin Faisal University (IAU) were invited to use the prototype. The students were first briefed on the prototype's usage and the user interface. Then, the students tested the system, and answered the survey questionnaire consisting of 10 items formulated to gauge the level of user satisfaction. The usability of the proposed system was also determined. The result as well as the level of usability of the system according to the feedback provided by 20 students can be referred in figure 10 . As can be construed by the result, a significant amount of users agrees that system is practical, useful and fulfill the project's primary objective.

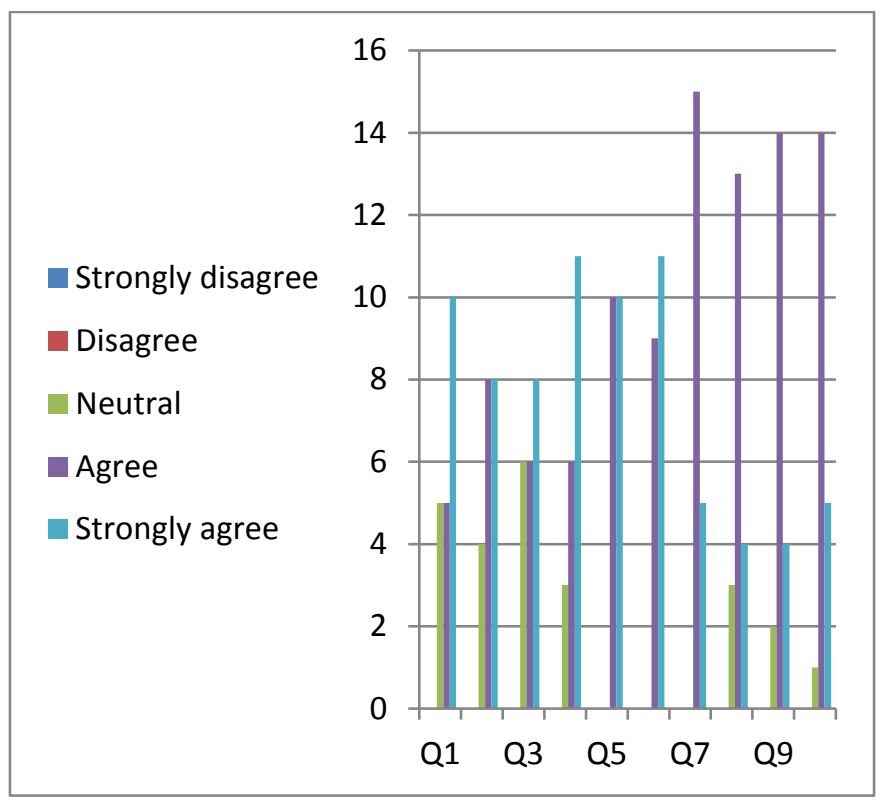

Figure 10: collected data results from the 20 students.

\section{v. CONCLUSION}

This paper highlights the best practices in building and designing a free Arab platform that acts as a collaborative medium between individuals. The platform aims to establish partnerships and cooperation agreements with regional and international leading institutions to exchange and develop skills and expertise. Also to improve and facilitate the process of communication between the parties to the maximum extent which ensures the success of the exchange process. The proposed system was developed using the Unified Modeling Language (UML) and Microsoft Visual Studio 2010 programming language.

\section{REFERENCES}

[1]. A. K. Lofters, M. B. Slater, E. Nicholas Angl, and F.-H. Leung, "Facebook as a tool for communication, collaboration, and informal knowledge exchange among members of a multisite family health team," Journal of 
multidisciplinary healthcare, vol. 9, pp. 29-34, 2016.

[2]. HelloPal, "http://www.hellopal.com/," 2019.

[3]. Edraak, "https://www.edraak.org/," 2019.

[4]. Rwaq, "www.rwaq.org," 2019.

[5]. M. k. Alsmadi, K. B. Omar, S. A. Noah, and I. Almarashdah, "Performance Comparison of Multi-layer Perceptron (Back Propagation, Delta Rule and Perceptron) algorithms in Neural Networks," in 2009 IEEE International Advance Computing Conference, 2009, pp. 296-299.

[6]. Z. Thalji and M. Alsmadi, "Iris Recognition using robust algorithm for eyelid, eyelash and shadow avoiding," World Applied Sciences Journal, vol. 25, pp. 858-865, 2013.

[7]. M. Alsmadi, U. A. Badawi, and H. E. Reffat, "A High Performance Protocol for Fault Tolerant Distributed Shared Memory (FaTP)," Journal of Applied Sciences, vol. 13, pp. 790-799, 2013.

[8]. F. HADDAD, J. ALFARO, and M. K. ALSMADI, "HOTELLING'S $\mathrm{T}^{2}$ CHARTS USING WINSORIZED MODIFIED ONE STEP M-ESTIMATOR FOR INDIVIDUAL NON NORMAL DATA," Journal of Theoretical \& Applied Information Technology, vol. 72, pp. 215-226, 2015.

[9]. F. Haddad and M. K. Alsmadi, "Improvement of The Hotelling's T2 Charts Using Robust Location Winsorized One Step M-Estimator (WMOM)," Journal of Mathematics (ISSN 1016-2526), vol. 50, pp. 97-112, 2018.

[10]. M. K. Alsmadi, U. A. Badawi, and H. M. Moharram, "SERVER FAILURES ENABLED JAVASPACES SERVICE," Journal of Computer Science, vol. 10, pp. 671-679, 2014.

[11]. M. K. Alsmadi, "Apparatus and method for lesions segmentation," ed: US Patent App. 15/614,893, 2018.
[12]. M. K. Alsmadi, "Facial expression recognition," ed: Google Patents, 2018.

[13]. R. Aldaej, L. Alfowzan, R. Alhashem, M. K. Alsmadi, I. Al-Marashdeh, U. A. Badawi, M. Alshabanah, D. Alrajhi, and M. Tayfour, "Analyzing, Designing and Implementing a Web-Based Auction online System," International Journal of Applied Engineering Research, vol. 13, pp. 8005-8013, 2018.

[14]. H. Almaimoni, N. Altuwaijri, F. Asiry, S. Aldossary, M. Alsmadi, I. Al-Marashdeh, U. A. Badawi, M. Alshabanah, and D. Alrajhi, "Developing and Implementing WEB-based Online Destination Information Management System for Tourism," International Journal of Applied Engineering Research, vol. 13, pp. 7541-7550, 2018.

[15]. I. A. Almrashdeh, N. Sahari, N. A. M. Zin, and M. Alsmadi, "Requirement analysis for distance learning management system students in Malaysian universities," Journal of Theoretical and Applied Information Technology, vol. 24, pp. 17-27, 2011.

[16]. M. k. Alsmadi, K. B. Omar, and S. A. Noah, "Proposed method to decide the appropriate feature set for fish classification tasks using Artificial Neural Network and Decision Tree," IJCSNS vol. 9, pp. 297-301, 2009.

[17]. N. Alsubaie, N. Althaqafi, E. Alradwan, F. AlHazza, M. Alsmadi, I. Al-Marashdeh, U. A. Badawi, M. Alshabanah, D. Alrajhi, S. Alsmadi, and M. Tayfour, "Analyzing and Implementing an Online Metro Reservation System," International Journal of Applied Engineering Research, vol. 13, pp. 9198-9206, 2018.

[18]. D. A. Daniyah Alkhaldi, Hajer Aldossary, Mutasem k. Alsmadi, Ibrahim Al-Marashdeh, Usama A Badawi, Muneerah Alshabanah, Daniah Alrajhi, "Developing and Implementing Web-based Online University Facilities 
Reservation System," International Journal of Applied Engineering Research, vol. 13, pp. 6700-6708, 2018.

[19]. i. Almarashdeh, M. K. Alsmadi, T. Farag, A. S. Albahussain, U. A. Badawi, N. Altuwaijri, H. Almaimoni, F. Asiry, S. Alowaid, M. Alshabanah, D. Alrajhi, A. A. Fraihet, and G. Jaradat, "Real-Time Elderly Healthcare Monitoring Expert System Using Wireless Sensor Network " International Journal of Applied Engineering Research, vol. 13, pp. 3517-3523, 2018.

[20]. M. K. S. Al Smadi, "Fish Classification Using Perceptron Neural Network," Centre for Graduate Studies, Universiti Utara Malaysia, 2007.

[21]. M. K. Alsmadi and U. A. Badawi, "Pattern matching in Rotated Images Using Genetic Algorithm," Journal of King Abdulaziz University Computing and Information vol. 5, pp. 53 - 59, 2017.

[22]. S. Aldossary, A. Althawadi, M. Almotairy, M. k. Alsmadi, D. Alrajhi, M. Alshabanah, I. AlMarashdeh, M. Tayfour, and R. Aljamaeen, "ANALYZING, DESIGNING AND IMPLEMENTING A WEB-BASED COMMAND CENTER SYSTEM," International Research Journal of Engineering and Technology, vol. 6, pp. 1008-1019, 2019.

[23]. R. A. Sheikh, R. Al-Assami, M. Albahr, M. A. Suhaibani, M. k. Alsmadi, M. Alshabanah, D. Alrajhi, I. Al-Marashdeh, H. Abouelmagd, and S. Alsmadi, "Developing and Implementing a Barcode Based Student Attendance System," International Research Journal of Engineering and Technology, vol. 6, pp. 497-506, 2019.

[24]. S. A. S. Ali, K. E. H. I. Eldaw, M. K. Alsmadi, and I. Almarashdeh, "Determinants of deposit of commercial banks in Sudan: an empirical investigation (1970-2012)," International
Journal of Electronic Finance, vol. 9, pp. 230255, 2019.

[25]. L. Eljawad, R. Aljamaeen, M. K. Alsmadi, I. AlMarashdeh, H. Abouelmagd, S. Alsmadi, F. Haddad, R. A. Alkhasawneh, M. Alzughoul, and M. B. Alazzam, "Arabic Voice Recognition Using Fuzzy Logic and Neural Network," International Journal of Applied Engineering Research, vol. 14, pp. 651-662, 2019.

[26]. A. M. Al Smadi, M. K. Alsmadi, H. Al Bazar, S. Alrashed, and B. S. Al Smadi, "Accessing Social Network Sites Using Work Smartphone for Face Recognition and Authentication," Research Journal of Applied Sciences, Engineering and Technology, vol. 11, pp. 5662, 2015.

[27]. M. Alsmadi, "Facial recognition under expression variations," Int. Arab J. Inf. Technol., vol. 13, pp. 133-141, 2016.

[28]. M. Alsmadi, K. Omar, and I. Almarashdeh, Fish Classification: Fish Classification Using Memetic Algorithms with Back Propagation Classifier: LAP LAMBERT Academic Publishing, 2012.

[29]. M. Alsmadi, K. Omar, S. Noah, and I. Almarashdeh, "A hybrid memetic algorithm with back-propagation classifier for fish classification based on robust features extraction from PLGF and shape measurements," Information Technology Journal, vol. 10, pp. 944-954, 2011.

[30]. M. Alsmadi, K. B. Omar, S. A. Noah, and I. Almarashdeh, "Fish Recognition Based on Robust Features Extraction from Size and Shape Measurements Using Neural Network " Journal of Computer Science, vol. 6, pp. 1088-1094, 2010

[31]. M. K. Alsmadi, "An efficient similarity measure for content based image retrieval using 
memetic algorithm," Egyptian Journal of Basic and Applied Sciences.

[32]. M. K. Alsmadi, "Query-sensitive similarity measure for content-based image retrieval using meta-heuristic algorithm," Journal of King Saud University - Computer and Information Sciences.

[33]. M. K. Alsmadi, A. Y. Hamed, U. A. Badawi, I. Almarashdeh, A. Salah, T. H. Farag, W. Hassan, G. Jaradat, Y. M. Alomari, and H. M. Alsmadi, "FACE IMAGE RECOGNITION BASED ON PARTIAL FACE MATCHING USING GENETIC ALGORITHM," SUST Journal of Engineering and Computer Sciences (JECS), vol. 18, pp. 51-61, 2017.

[34]. M. K. Alsmadi, K. B. Omar, S. A. Noah, and I. Almarashdeh, "Fish recognition based on robust features extraction from color texture measurements using back-propagation classifier," Journal of Theoritical and Applied Information Technology, vol. 18, 2010.

[35]. U. A. Badawi and M. K. Alsmadi, "A GENERAL FISH CLASSIFICATION METHODOLOGY USING META-HEURISTIC ALGORITHM WITH BACK PROPAGATION CLASSIFIER," Journal of Theoretical \& Applied Information Technology, vol. 66, pp. 803-812, 2014.

[36]. M. Yousuf, Z. Mehmood, H. A. Habib, T. Mahmood, T. Saba, A. Rehman, and M. Rashid, "A Novel Technique Based on Visual Words Fusion Analysis of Sparse Features for Effective Content-Based Image Retrieval," Mathematical Problems in Engineering, vol. 2018, 2018.

[37]. R. R. Saritha, V. Paul, and P. G. Kumar, "Content based image retrieval using deep learning process," Cluster Computing, pp. 1-14, 2018.

[38]. M. K. Alsmadi, K. B. Omar, and S. A. Noah, "Fish recognition based on robust features extraction from size and shape measurements using back-propagation classifier," International Review on Computers and Software, vol. 5, pp. 489-494, 2010.

[39]. M. K. Alsmadi, K. B. Omar, S. A. Noah, and I. Almarashdeh, "Fish recognition based on robust features extraction from size and shape measurements using neural network," Journal of Computer Science, vol. 6, p. 1088, 2010.

[40]. M. K. S. Alsmadi, K. B. Omar, S. A. Noah, and I. Almarashdah, "Fish recognition based on the combination between robust feature selection, image segmentation and geometrical parameter techniques using Artificial Neural Network and Decision Tree," arXiv preprint arXiv:0912.0986, 2009.

[41]. M. Alsmadi, K. B. Omar, and S. A. Noah, "Back propagation algorithm: the best algorithm among the multi-layer perceptron algorithm," International Journal of Computer Science and Network Security, vol. 9, pp. 378-383, 2009.

[42]. M. Alsmadi, K. Omar, S. Noah, I. Almarashdeh, S. Al-Omari, P. Sumari, S. Al-Taweel, A. Husain, N. Al-Milli, and M. Alsmadi, "Fish recognition based on robust features extraction from size and shape measurements using neural network," Information Technology Journal, vol. 10, pp. 427-434, 2009.

[43]. T. H. Farag, W. A. Hassan, H. A. Ayad, A. S. AlBahussain, U. A. Badawi, and M. K. Alsmadi, "Extended Absolute Fuzzy Connectedness Segmentation Algorithm Utilizing Region and Boundary-Based Information," Arabian Journal for Science and Engineering, pp. 1-11, 2017.

[44]. M. K. Alsmadi, "A hybrid Fuzzy C-Means and Neutrosophic for jaw lesions segmentation," Ain Shams Engineering Journal.

[45]. U. A. Badawi and M. K. S. Alsmadi, "A Hybrid Memetic Algorithm (Genetic Algorithm and Great Deluge Local Search) With BackPropagation Classifier for Fish Recognition " 
International Journal of Computer Science Issues, vol. 10, pp. 348-356, 2013.

[46]. A. M, O. K, and N. S, "Back Propagation Algorithm : The Best Algorithm Among the Multi-layer Perceptron Algorithm," International Journal of Computer Science and Network Security, vol. 9, pp. 378-383, 2009.

[47]. M. Sharma, G. Purohit, and S. Mukherjee, "Information Retrieves from Brain MRI Images for Tumor Detection Using Hybrid Technique K-means and Artificial Neural Network (KMANN)," in Networking Communication and Data Knowledge Engineering, ed: Springer, 2018, pp. 145-157.

[48]. Y. Gao, X. Li, M. Dong, and H.-p. Li, "An enhanced artificial bee colony optimizer and its application to multi-level threshold image segmentation," Journal of Central South University, vol. 25, pp. 107-120, 2018.

[49]. M. K. Alsmadi, "A hybrid firefly algorithm with fuzzy-C mean algorithm for MRI brain segmentation," American Journal of Applied Sciences, vol. 11, pp. 1676-1691, 2014.

[50]. M. K. Alsmadi, "MRI brain segmentation using a hybrid artificial bee colony algorithm with fuzzy-c mean algorithm," Journal of Applied Sciences, vol. 15, p. 100, 2015.

[51]. M. K. Alsmadi, "A hybrid Fuzzy C-Means and Neutrosophic for jaw lesions segmentation," Ain Shams Engineering Journal, 2017.

[52]. S. H. Park and K. Han, "Methodologic Guide for Evaluating Clinical Performance and Effect of Artificial Intelligence Technology for Medical Diagnosis and Prediction," Radiology, p. 171920, 2018.

[53]. D. S. Kermany, M. Goldbaum, W. Cai, C. C. Valentim, H. Liang, S. L. Baxter, A. McKeown, G. Yang, X. Wu, and F. Yan, "Identifying Medical Diagnoses and Treatable Diseases by
Image-Based Deep Learning," Cell, vol. 172, pp. 1122-1131. e9, 2018.

[54]. I. Almarashdeh, "Sharing instructors experience of learning management system: A technology perspective of user satisfaction in distance learning course," Computers in Human Behavior, vol. 63, pp. 249-255, 2016.

[55]. I. ALMARASHDEH, H. BOUZKRAOUI, A. AZOUAOUI, H. YOUSSEF, L. NIHARMINE, A. A. RAHMAN, S. S. S. YAHAYA, A. M. A. ATTA, D. A. EGBE, and B. M. MURIMO, "AN OVERVIEW OF TECHNOLOGY EVOLUTION: INVESTIGATING THE FACTORS INFLUENCING NON-BITCOINS USERS TO ADOPT BITCOINS AS ONLINE PAYMENT TRANSACTION METHOD," Journal of Theoretical and Applied Information Technology, vol. 96, 2018.

[56]. I. Almarashdeh, "The important of service quality and the trust in technology on users perspectives to continues use of mobile services," Journal of Theoretical \& Applied Information Technology, vol. 96, 2018.

[57]. I. Almarashdeh and M. Alsmadi, "Investigating the acceptance of technology in distance learning program," in Information Science and Communications Technologies (ICISCT), International Conference on, Tashkent Uzbekistan 2016, pp. 1-5.

[58]. I. Almarashdeh and M. Alsmadi, "Heuristic evaluation of mobile government portal services: An experts' review," in 11th International Conference for Internet Technology and Secured Transactions (ICITST), 2016, pp. 427-431.

[59]. I. Almarashdeh and M. K. Alsmadi, "How to make them use it? Citizens acceptance of $\mathrm{M}$ government," Applied Computing and Informatics, vol. 13, pp. 194-199, 2017/07/01/ 2017. 
[60]. I. Almarashdeh and M. K. Alsmadi, "Applied Computing and Informatics," 2017.

[61]. I. Almarashdeh, A. Althunibat, and N. F. Elias, "Developing a Mobile Portal Prototype for Egovernment Services," Journal of Applied Sciences, vol. 14, pp. 791-797, 2014.

[62]. I. Almarashdeh, A. Althunibat, N. Fazidah Elias, A. Adewumi, A. Al Thunibat, N. Zin, N. Ashaari, A. Al Thunibat, N. Zin, and N. Sahari, "E-Government for mobile societiesstocktaking of current trends and initiatives," Journal of Applied Sciences, vol. 14, pp. 104111, 2013.

[63]. I. Almarashdeh, N. F. Elias, N. Sahari, and N. Zain, "Development of an interactive learning management system for malaysian distance learning institutions," Middle East Journal of Scientific Research, vol. 14, pp. 1471-1479, 2013.

[64]. I. AlMarashdeh, G. M. Jaradat, M. Ayob, A. Abu-Al-Aish, and M. Alsmadi, "An Elite PoolBased Big Bang-Big Crunch Metaheuristic for Data Clustering," Journal of Computer Science, 2018.

[65]. I. Almarashdeh, N. Sahari, and N. Mat Zin, "Heuristic evaluation of distance learning management system interface," presented at the International Conference on Electrical Engineering and Informatics Bandung, Indonesia 2011.

[66]. I. Almarashdeh, N. Sahari, N. M. Zin, and M. Alsmadi, "Instructors acceptance of Distance Learning Management System," in International Symposium on Information Technology 2010 (ITSim 2010), Kuala Lumpur, 2010, pp. 1-6.

[67]. I. A. Almarashdeh, N. Sahari, N. A. H. M. Zin, and M. Alsmadi, "Distance learners acceptance of learning management system," in 2nd International Conference on Data Mining and
Intelligent Information Technology Applications (ICMIA2010), Seoul, Korea, 2010, pp. 304-309.

[68]. I. A. Almarashdeh, N. Sahari, N. A. H. M. Zin, and M. Alsmadi, "Distance Learning Management System requirements From Student's Perspective," The international Journal of Theoretical and Applied Information Technology, vol. 24, 2011.

[69]. I. A. Almarashdeh, N. Sahari, and N. A. M. Zin, "Heuristic evaluation of distance learning management system interface," in Electrical Engineering and Informatics (ICEEI), 2011 International Conference on, 2011, pp. 1-6.

[70]. I. A. Almarashdeh, N. Sahari, N. a. M. Zin, and M. Alsmad, "The Success of Learning Management System Among Distance Learners in Malaysian Universitie," Journal of Theoretical and Applied Information Technology, vol. 21 pp. 80-91, 2010.

[71]. I. A. Almarashdeh, N. Sahari, N. A. M. Zin, and M. Alsmadi, "THE SUCCESS OF LEARNING MANAGEMENT SYSTEM AMONG DISTANCE LEARNERS IN MALAYSIAN UNIVERSITIES," Journal of Theoretical \& Applied Information Technology, vol. 21, 2010.

[72]. I. A. Almarashdeh, N. Sahari, N. A. M. Zin, and M. Alsmadi, "Acceptance of learning management system: A comparison between distance learners and instructors," Advances in Information Sciences and Service Sciences, vol. 3, pp. 1-9, 2011.

[73]. I. A. E. Almarashdeh, "Study of the Usability of Learning Management System Tool (Learning Care) of Postgraduate Students in University Utara Malaysia (UUM)," Graduate School, Universiti Utara Malaysia, 2007.

[74]. I. A. Almrashdah, N. Sahari, N. A. H. M. Zin, and M. Alsmadi, "Distance learners acceptance of learning management system," in Advanced 
Information Management and Service (IMS), 2010 6th International Conference on, 2010, pp. 304-309.

[75]. I. A. Almrashdah, N. Sahari, N. A. H. M. Zin, and M. Alsmadi, "Instructors acceptance of distance learning management system," in Information Technology (ITSim), 2010 International Symposium in, 2010, pp. 1-6.

[76]. I. A. ALMRASHDEH, N. SAHARI, N. A. M. ZIN, and M. ALSMADI, "DISTANCE LEARNING MANAGEMENT SYSTEM REQIUREMENTS FROM STUDENT'S PERSPECTIVE," Journal of Theoretical \& Applied Information Technology, vol. 24, 2011.

[77]. I. A. Almrashdeh, N. Sahari, N. A. M. Zin, and M. Alsmadi, "Instructor's success measures of Learning Management System," in Electrical Engineering and Informatics (ICEEI), 2011 International Conference on, 2011, pp. 1-7.

[78]. M. K. A. Ibrahim Almarashdeh, Ghaith Jaradat, Ahmad Althunibat, Sami Abdullah Albahussain, Yousef Qawqzeh, Usama A Badawi, Tamer Farag, "Looking Inside and Outside the System: Examining the Factors Influencing Distance Learners Satisfaction in Learning Management System," Journal of Computer Science, vol. 14, pp. 453-465, 2018.

[79]. G. Jaradat, M. Ayob, and I. Almarashdeh, "The effect of elite pool in hybrid population-based meta-heuristics for solving combinatorial optimization problems," Applied Soft Computing, vol. 44, pp. 45-56, 2016.

[80]. G. M. Jaradat, A. Al-Badareen, M. Ayob, M. AlSmadi, I. Al-Marashdeh, M. Ash-Shuqran, and E. Al-Odat, "Hybrid Elitist-Ant System for Nurse-Rostering Problem," Journal of King Saud University-Computer and Information Sciences, 2018.

[81]. M. Rasmi, M. B. Alazzam, M. K. Alsmadi, I. A. Almarashdeh, R. A. Alkhasawneh, and S.
Alsmadi, "Healthcare professionals' acceptance Electronic Health Records system: Critical literature review (Jordan case study)," International Journal of Healthcare Management, pp. 1-13, 2018.

[82]. M. K. Alsmadi, "Forecasting River Flow in the USA Using a Hybrid Metaheuristic Algorithm with Back-Propagation Algorithm," Scientific Journal of King Faisal University (Basic and Applied Sciences), vol. 18, pp. 13-24, 2017.

[83]. J. Adeyemo, O. Oyebode, and D. Stretch, "River Flow Forecasting Using an Improved Artificial Neural Network," in EVOLVE-A Bridge between Probability, Set Oriented Numerics, and Evolutionary Computation VI, ed: Springer, 2018, pp. 179-193.

[84]. A. Ahani, M. Shourian, and P. R. Rad, "Performance Assessment of the Linear, Nonlinear and Nonparametric Data Driven Models in River Flow Forecasting," Water Resources Management, pp. 1-17, 2018.5B. Göranzon and I. Josefson, Knowledge, skill and artificial intelligence: Springer Science \& Business Media, 2012.

[85]. R. Ennals, B. Göranzon, B. Nelson, and D. Alvunger, "Dialogue, skill and tacit knowledge: Practical knowledge and corporate social responsibility," in Cultural Roots of Sustainable Management, ed: Springer, 2016, pp. 153-163.

[86]. J. Grudzień, "The Development of Computer Competencies Using Artificial Intelligence," International Journal of Information and Communication Technologies in Education, vol. 3, pp. 40-56, 2014.

[87]. M. Fontoura, W. Pree, and B. Rumpe, "UML-F: A modeling language for object-oriented frameworks," in European Conference on Object-Oriented Programming, 2000, pp. 6382. 
[88]. 1. Teixeira, A. R. Xambre, J. Figueiredo, and H. Alvelos, "Analysis and design of a project management information system: practical case in a consulting company," in CENTERIS/ProjMAN/HCis, 2016, pp. 171-178.

[89]. I. Almarashdeh, N. F. Elias, N. Sahari, and N. A. M. Zain, "Development of an interactive learning management system for malaysian distance learning institutions. ," Middle East Journal of Scientific Research, 14(11), . 10.5829/idosi.mejsr.2013.14.11.2339, vol. 14, pp. 1471-1479, 2013.

[90]. D. Rajagopal and K. Thilakavalli, "A Study: UML for OOA and OOD," International Journal of Knowledge Content Development \& Technology, vol. 7, pp. 5-20, 2017.

[91]. M. Torchiano, G. Scanniello, F. Ricca, G. Reggio, and M. Leotta, "Do UML object diagrams affect design comprehensibility? Results from a family of four controlled experiments," Journal of Visual Languages \& Computing, vol. 41, pp. 10-21, 2017/08/01/ 2017.

[92]. S. I. Bello, R. O. Bello, A. O. Babatunde, M. Olugbebi, and B. O. Bello, "A University Examination Web Application Based on LinearSequential Life Cycle Model," 2017.

[93]. I. Almarashde, A. Althunibat, and N. Fazidah El, "Developing a Mobile Portal Prototype for E-government Services," Journal of Applied Sciences, vol. 14, pp. 791-797, 2014.

[94]. D. S. Al-Omairi, W. H. AlNasheri, W. Y. AlQarni, I. Almarashdeh, M. k. Alsmadi, M. Alshabanah, and D. Alrajhi, "Developing and Implementing A Web-Based Recycling System For Protecting The Green Environment," International Journal of Software Engineering \& Applications, vol. 10, pp. 59-72, 2019.
[95]. R. Ibrahim, "Formalization of the data flow diagram rules for consistency check," arXiv preprint arXiv:1011.0278, 2010.

[96]. N. A. Nora Alsubaie, Eman Alradwan, Fatima Al-Hazza, Mutasem Alsmadi, Ibrahim AlMarashdeh, Usama A Badawi, Muneerah Alshabanah, Daniah Alrajhi, Sanaa Alsmadi, Mohammed Tayfour., "Analyzing and Implementing an Online Metro Reservation System," International Journal of Applied Engineering Research, vol. 13, pp. 9198-9206, 2018.

\section{Cite this article as :}

Amani Al-Ghamdi, Dalal Al Harbi, Naseebah Alarfaj, Bandar Al Hajri, Ibrahim Almarashdeh, Mutasem k. Alsmadi, Muneerah Alshabanah, Daniah Alrajhi, "Developing and Implementing a Web-Based Platform for Skills and Knowledge Exchange", International Journal of Scientific Research in Science and Technology (IJSRST), Online ISSN : 2395-602X, Print ISSN : 2395-6011, Volume 6 Issue 3, pp. 562-573, May-June 2019. Available at doi : https://doi.org/10.32628/IJSRST196345 Journal URL : http://ijsrst.com/IJSRST196345 